\title{
Availability, pricing and affordability of essential medicines in Eastern Ethiopia: a comprehensive analysis using $\mathrm{WHO} / \mathrm{HAI}$ methodology
}

\author{
Mekonnen Sisay ${ }^{1 *} \mathbb{0}$, Firehiwot Amare ${ }^{2}$, Bisrat $\operatorname{Hagos}^{3}$ and Dumessa Edessa²
}

\begin{abstract}
Background: Access to essential medicines is a universal human right and availability and affordability are the preconditions for it. In line with the sustainable development goals, World Health Organization (WHO) has outlined a framework that assists the policy makers to improve access to essential medicines for universal health coverage by 2030 . However, the availability and affordability of essential medicines remains suboptimal in several low-income countries. Therefore, this study was designed to investigate the availability, pricing and affordability of essential medicines in eastern Ethiopia.

Methods: A cross-sectional study design was employed to conduct this study. Public and private health facilities found in Eastern Ethiopia and which fulfilled criteria set forth by WHO/Health Action International (HAI) guideline and essential medicines listed on WHO/HAl guideline and essential medicine list of Ethiopia were included. Accordingly, 60 medicine outlets were selected based on the WHO/HAl standardized sampling methodology. A standardized data collection tools developed by WHO/HAl, with necessary modifications, was employed to collect the data. Median Price Ratio (MPR) was computed as a ratio of median local buyers' price to international buyers' reference price. The Mann-Whitney $U$ test was employed to compare the median buyers' price between public and private health facilities. Kruskal-Wallis test was also run to explore the median price difference among all facilities. Treatment affordability was calculated based on the number of days of wage of the lowest-paid government employee of Ethiopia required to purchase the prescribed regimen.

Results: The overall percent availability of originator brand (OB) versions of essential medicines was found to be $3.6 \%$ (range: $0.0-31.7 \%$ ), with the public and private sectors contributing $1.43 \%$ and $5.50 \%$, respectively. The overall percent availability of lowest price generics (LPGs) was $46.97 \%$ (range: 1.7-93.3\%) (Public: 42.5\%; private: 50.8\%). Only eight LPGs (16.0\%) met the WHO target of $80 \%$. The Mann-Whitney $U$ test indicated that $64 \%$ drugs showed statistically significant median price difference between public and private settings $(p<0.05)$. The MPR value indicated that the median buyers' price of drugs in private sector were more than four times the international reference price in $30 \%$ of drugs. The percentage of unaffordable medicine were 72.09 and $91.84 \%$ for public and private facilities, respectively, with $79.17 \%$ of the medicines were unaffordable when both settings were combined.
\end{abstract}

\footnotetext{
*Correspondence: mekonnensisay27@yahoo.com

1 Department of Pharmacology and Toxicology, School of Pharmacy,

College of Health and Medical Sciences, Haramaya University, P.O.

Box 235, Harar, Ethiopia

Full list of author information is available at the end of the article
} original author(s) and the source, provide a link to the Creative Commons licence, and indicate if changes were made. The images or other third party material in this article are included in the article's Creative Commons licence, unless indicated otherwise in a credit line to the material. If material is not included in the article's Creative Commons licence and your intended use is not permitted by statutory regulation or exceeds the permitted use, you will need to obtain permission directly from the copyright holder. To view a copy of this licence, visit http://creativecommons.org/licenses/by/4.0/. The Creative Commons Public Domain Dedication waiver (http://creativeco mmons.org/publicdomain/zero/1.0/) applies to the data made available in this article, unless otherwise stated in a credit line to the data. 
Conclusion: Only $16 \%$ of the surveyed medicines surpassed the WHO cut-off point of $80 \%$. Nearly one-third of drugs in the private sector had a price of more than four times compared to the international reference prices. Moreover, four out of five drugs were found unaffordable when both settings were combined, demanded several days of wage of lowest paid government employee. This finding calls a prompt action from stakeholders to devise a strategy that help promote the access of essential medicines and rescue the struggling healthcare system of Ethiopia.

Keywords: Availability, Price, Affordability, Essential medicines, Medicine outlets, WHO/HAI

\section{Background}

Health is a fundamental human right while access to health care is a way of ensuring the fulfillment of this right [1]. Universal health coverage (UHC) as the main target of sustainable development goal strives to achieve access to quality health services according to the need, while ensuring imposition of less financial hardship on the users of the services [2]. The realization of UHC have the access of essential medicines (EMs) at its core as they are an indispensable element for delivery of services and a requirement for high-quality care [3].

Availability and affordability are dimensions of measures of access to medicines in health systems [4]. Access to affordable, quality-assured EMs is crucial to reducing the financial burden of care, preventing greater pain and suffering, shortening the duration of illness, and averting needless disabilities and deaths worldwide [5]. However, one third of the world's population lacks regular access to EMs, resulting a cascade of preventable misery and suffering $[6,7]$. This estimate rises to over $40 \%$ in lowincome countries and over $50 \%$ in poorest countries of Asia and Africa despite the issuance of legislations supporting the implementation of UHC by the countries [8].

EMs satisfy the priority health care needs of the population. They are intended to be available within the context of functioning health systems at all times in adequate amounts, in the appropriate dosage forms, with assured quality, and at a price, the individual and the community can afford $[9,10]$. In many developing countries, lack of financial resources or information can create barriers to accessing essential medicines and contributing for the increased rate of morbidity and mortality $[11,12]$. On top of unavailability of EMs, high price of medicines is posing a problem in the provision of health services [13]. Price of medicines is a concern in low- and middle-income countries where up to $90 \%$ of the population purchases medicines through out-of-pocket payments [14]. This has a huge impact on the affordability of medicines and treatment outcome of diseases [15].

In the mid-1990s, civil society organizations in developed and developing countries started drawing attention to the need for increased access to essential medicines as part of the fight against poverty. Later, the World Health Organization/Health Action International (WHO/HAI) project was established in 2001 to deal with medicine prices and availability. The main focus of this project was to develop a reliable methodology for collecting and analyzing availability, affordability and medicine price component data across healthcare sectors and regions; to publish survey data to improve price transparency; and to advocate for appropriate national policies and strategies. Through series of improvements, this guideline has been used to measure medicine prices, availability, and affordability throughout the globe [16-18].

Ethiopia is one of the developing nations facing the dire consequences of unavailability and unaffordability of medicines [19]. To this end, studies conducted in the country are limited in the provision of region-specific price, availability and affordability data on EMs. Therefore, this study was designed to assess the price, availability and affordability of EMs in Eastern Ethiopia by using WHO/HAI survey methodology.

\section{Methods \\ Study area, design and period}

The study was conducted at public and private healthcare facilities in the major cities of Eastern Ethiopia including Dire Dawa, Harar, Haramaya, Chiro, Degahabour and Jigjiga. Dire Dawa is located $515 \mathrm{~km}$ east of Addis Ababa with a total area of $1288.02 \mathrm{~km}^{2}$. The area is dominated by dry, windy and hot climatic condition. According to the projections made based on the 2015 census, the total population of the administration is 383,529 of whom 283,773 (74\%) live in urban part of the city. Harar is located 526 $\mathrm{km}$ away from Addis Ababa to the East. Harari Region is one of the nine National Regional States of Ethiopia, with the town of Harar as its capital. Based on the 2015 census, Harari had a total population of 183,344 , of whom 92,258 were males and 99,321 or $54.17 \%$ of the population were urban inhabitants. Jigjiga is another major city in eastern Ethiopia, mainly inhabited by different Somali clans. Based on figures from the central statistics agency (CSA) in 2015, Jigjiga has an estimated total population of 250,000 of whom 126,578 were females. Haramaya is also one of the administrative centers in eastern Ethiopia located at a distance of $508 \mathrm{~km}$ from the capital, Addis Ababa. The 2015 national census reported a total population of 271,018 , of whom 138,282 were males and $18.46 \%$ 
of its population were urban dwellers. Chiro, the capital of West Hararghe zone, is another major city in the eastern part of Ethiopia located at $373 \mathrm{~km}$ from Addis Ababa. The 2015 national census reported a total population for this town of 33,670, of whom 18,118 were males. Another city included in the study is Degehabur which is located in the Somali region of Ethiopia. Based on figures from the CSA in 2007, it had an estimated total population of 30,027 of whom 16,474 were males. A cross-sectional study was conducted from March 01- March 31, 2020.

\section{Population}

All public and private healthcare facilities of Eastern Ethiopia were considered as a source population. Public and private healthcare facilities found in Eastern Ethiopia and which fulfilled criteria set forth by WHO/HAI guideline as well as essential medicines listed on WHO/HAI guideline and essential medicine list (EML) of Ethiopia were included for the study. Non-governmental health facilities, health facilities that provide medications free of cost and programmed essential medicines were excluded from this study.

\section{Sample size determination}

Sixty medicine outlets were selected based on the WHO/ HAI standardized sampling methodology [16]. Besides, WHO/HAI recommended that such price-based studies should include at least 14 global core medicines, and where possible 16 regional core medicines. Based on this, 30 drugs from global/regional core lists $[16,17]$ plus 20 other essential medicines from EML of Ethiopia [20] were included, making a total of 50 essential medicines per site, from different therapeutic classes for this study. This will enable the price and availability dynamics of the therapeutic group of medicines to be compared to those of other essential medicines which may be very meaningful in the interpretation of the findings and development of recommendation and strategies. It will also enable the publicly accessible global database of prices and availability to expand.

\section{Sampling procedure and technique}

Based on the WHO/HAI standard sampling technique, six survey areas which cover a population of about 100,000 to 250,000 , reachable within one day's travel from the main urban center, large enough to represent the survey region and containing the requisite number of health facilities were selected [16, 17]. Based on this: Dire Dawa, Harar, Haramaya, Chiro, Degahabour and Jigjiga were selected as a survey area. In order to select the medicine outlets for the study based on WHO/HAI standard sampling technique, one main public hospital (referral, district or regional hospital) was selected from each survey area. Then, other four public health facilities, and five private medicine outlets, which are within 3-h travel from the main public hospital, were selected by using simple random sampling. In addition to the global and regional core list of essential medicines, 20 more essential medicines were randomly selected from EML of Ethiopia. The summary of generic name of essential medicines, strengths and unit of measurements, originator brands (OBs) and their respective manufacturers was presented in Table 1.

\section{Data collection methods}

A standardized data collection tool developed by WHO/ HAI, with necessary modifications was employed to collect the data from both public and private facilities. The data were collected by twelve pharmacists who were recruited as data collectors. The data regarding price and availability of essential medicines were collected from each selected drug retail outlet.

\section{Study variables}

The availability, price and affordability of essential medicines were considered as the outcome variables. Type of sector, source of drugs (local or imported), the nature of facilities, duration of therapy, monthly income of lowest paid government worker (to be converted to daily wage), the type of medicines (OBs and LPGs) were treated as independent variables.

\section{Data processing and analysis}

After data collection, data were entered and analyzed using Excel ${ }^{\circledR}$ WHO/HAI Medicine Pricing Workbook and the results were summarized and presented in tables and graphs. Medicine availability was calculated as percent availability of individual medicines; mean (average) percent (\%) availability across a group of medicines; and variations between product types (OBs vs LPGs) and sectors. For further statistical analysis, the data were transferred to SPSS version 20. Normality distribution of the price data was checked using Kolmogorov-Smirnov and Shapiro-Wilk tests. Accordingly, the Wilcoxon-MannWhitney $U$ test was employed to compare the median buyers' price (customers' out-of-pocket expenditure for drugs) between public and private health facilities. Kruskal-Wallis test was also run to explore the median price difference among four facilities (hospital, health center, pharmacy and drug store). Medicine prices were calculated as median prices of individual medicines in United States Dollar (USD). The exchange rate of Ethiopian birr to USD equivalent was considered by taking the monthly average of March, 2020 ( 1 USD $=35.70$ Ethiopian birr).; median price ratio (MPR) was computed as ratios of median local price to international (WHO/HAI) 
Table 1 List of essential medicines included in the analysis

\begin{tabular}{|c|c|c|c|}
\hline Generic name & Dosage form and strength & Originator brand (OB) & Manufacturer \\
\hline 1. Salbutamol & Inhaler, $0.1 \mathrm{mg} /$ dose & Ventoline & GSK \\
\hline 2. Metformin & Tablet, 500 mg & Glucophage & Bristol-Myers Squibb \\
\hline 3. Bisoprolol & Cap/tab, 5 mg & Concor & Merck \\
\hline 4. Captopril & Tab, 25 mg & Capoten & BMS \\
\hline 5. Simvastatin & Cap/tab, $20 \mathrm{mg}$ & Zocor & MSD \\
\hline 6. Amitriptyline & Cap/tab, 25 mg & Tryptizol & MSD \\
\hline 7. Ciprofloxacin & Cap/tab, 500 mg & Ciproxin & Bayer \\
\hline 8. Co-trimoxazole & Suspension, $40+200 \mathrm{mg} / 5 \mathrm{ml}$ & Bactrim & Roche \\
\hline 9. Amoxicillin & Cap/tab, 500 mg & Amoxil & GSK \\
\hline 10. Ceftriaxone & Injection, $1 \mathrm{~g} / \mathrm{vial}$ & Rocephin & Roche \\
\hline 11. Diazepam & Cap/tab, 5 mg & Valium & Roche \\
\hline 12. Diclofenac & Cap/tab, $50 \mathrm{mg}$ & Voltaren/cataflam & Novartis \\
\hline 13. Paracetamol & Suspension, $24 \mathrm{mg} / \mathrm{ml}$ & Panadol & GSK \\
\hline 14. Omeprazole & Cap/tab, $20 \mathrm{mg}$ & Losec & Astra Zeneca \\
\hline 15. Glibenclamide & Cap/tab, 5 mg & Daonil & Sanofi-Aventis \\
\hline 16. Atenolol & Cap/tab, $50 \mathrm{mg}$ & Tenormin & Astra Zeneca \\
\hline 17. Hyoscine Butylbromide & Tab, $10 \mathrm{mg}$ & Buscopan & Sanofi-Aventis \\
\hline 18. Metoclopramide $\mathrm{HCl}$ & Tab, $10 \mathrm{mg}$ & Maxolon & GSK \\
\hline 19. Bisacodyl & Tab, $5 \mathrm{mg}$ & Dulcolax & Sanofi-Aventis \\
\hline 20. Oral rehydration salt & $1 \mathrm{~L}$ powder & - & - \\
\hline 21. Loperamide & Cap, 2 mg & Imodium & Johnson and Johnson \\
\hline 22. Amiodarone & Tab, $200 \mathrm{mg}$ & Cordarone & Sanofi-Aventis \\
\hline 23. Furosemide & Tab, $40 \mathrm{mg}$ & Lasix & Hoechst/Sanofi Aventis \\
\hline 24. Adrenaline & Injection, 0.1\%, 1:1000 $1 \mathrm{mg} / \mathrm{ml}$ & - & - \\
\hline 25. Paracetamol & Tab, $500 \mathrm{mg}$ & Panadol & GSK \\
\hline 26. Acetylsalicylic Acid & Tab, $300 \mathrm{mg}$ & Aspirin & Bayer \\
\hline 27. Acetylsalicylic Acid & Tab, $100 \mathrm{mg}$ & Aspirin & Bayer \\
\hline 28. Ibuprofen & Tab, $400 \mathrm{mg}$ & Brufen & Abbott \\
\hline 29. Fluoxetine & Cap, 20 mg & Prozac & Lilly \\
\hline 30. Sodium Valproate & Tab, $200 \mathrm{mg}$ & Epilim & Sanofi-Aventis \\
\hline 31. Risperidone & Tab, $1 \mathrm{mg}$ & Risperdal & Jansen Cilag \\
\hline 32. Haloperidol & Tab, 5 mg (0.5 mg) & Haldol & Jansen Cilag \\
\hline 33. Carbamazepine & Tab, $200 \mathrm{mg}$ & Tegretol & Novartis \\
\hline 34. Allopurinol & Tab, $100 \mathrm{mg}$ & Zyloprim & Mylan \\
\hline 35. Amoxicillin & Cap, 500 mg & Amoxil & GSK \\
\hline 36. Ampicillin & Injection (Sodium), 500 mg in vial & Totapen & BMS \\
\hline 37. Cloxacillin Sodium & Cap, 500 mg & Orbenine & Pfizer \\
\hline 38. Penicillin G Benzanthine & Injection 2.4, MIU In Vial & Penadur & Wyeth \\
\hline 39. Azithromycin & Cap, $250 \mathrm{mg}$ & Zithromax & Pfizer \\
\hline 40. Ceftazidime & Injection $1 \mathrm{~g}$ in vial & Fortum & GSK \\
\hline 41. Doxycycline & Cap, 100 mg & Vibramycin & Pfizer \\
\hline 42. Metronidazole & Cap, $250 \mathrm{mg}$ & Flagyl & Sanofi-Aventis \\
\hline 43. Co-trimoxazole & $\mathrm{Tab}, 400 \mathrm{mg}+80 \mathrm{mg}$ & Bactrim & Roche \\
\hline 44. Fluconazole & Tab, $200 \mathrm{mg}$ & Diflucan & Pfizer \\
\hline 45. Clindamycin & Cap, $150 \mathrm{mg}$ & Cleocin & Pfizer \\
\hline 46. Hydrocortisone & Injection $50 \mathrm{mg} / \mathrm{ml}$ in $2 \mathrm{ml}$ ampoule & Solu-Cortef & Pfizer \\
\hline 47. Propylthiouracil & $\mathrm{Tab}, 50 \mathrm{mg}$ & - & - \\
\hline 48. Ferrous sulphate + Folic Acid & Cap, $200 \mathrm{mg}+0.5 \mathrm{mg}$ & - & - \\
\hline 49. Tetracycline $\mathrm{HCl}$ & Eye ointment, $1 \%$ & Aureomycine & Frilab \\
\hline
\end{tabular}


Table 1 (continued)

\begin{tabular}{llll}
\hline Generic name & Dosage form and strength & Originator brand (OB) & Manufacturer \\
\hline 50. Albendazole & Tab, $200 \mathrm{mg}$ & Zentel & GSK \\
\hline
\end{tabular}

buyers' reference price for public, private and overall facilities as follows.

paracetamol suspension, diclofenac 50 tab, glibenclamide $5 \mathrm{mg}$ tab, salbutamol inhaler, ibuprofen 400 tab

$$
\mathrm{MPR}=\frac{\text { Median price of a given drug (USD) }}{\text { International buyers' median price of that drug (USD) }}
$$

Treatment affordability was calculated based on the daily wage of the lowest-paid government employee; and components of the prices of medicines paid by consumers. Daily wage of the lowest paid government worker of Ethiopia was about 0.44 USD (https://mywage.org/ethio pia/labour-law/wages). Accordingly, the affordability was also computed for public and private sectors for ease of comparison. Affordability (in terms of the number of daily wages) was computed as follows: and ASA 100 tab were available in private sectors only. The overall availability of $\mathrm{OB}$ versions of 50 essential medicines in private sector was about $5.50 \%$ with pharmacy and drug store contributing $6.1 \%$ and $4.5 \%$, respectively (Table 2).

Regarding the LPG versions of these essential medicines, all the LPG versions of selected essential medicines were available at least in one of the surveyed health facilities. The overall percent availability of LPGs in all settings

$$
\text { Affordability }=\frac{\text { The total price of the regimen for a given drug (USD) }}{\text { The daily wage of lowest paid government employee (USD) }}
$$

\section{Result}

\section{Availability of essential medicines}

In 60 health facilities surveyed, nearly half $(n=26)$ of the $\mathrm{OB}$ versions of essential medicines were not available at all during the study. From which, 6 OB medicines out of $14 \mathrm{WHO} / \mathrm{HAI}$ core drugs were not available at all. Besides, only four OB essential medicines (glibenclamide $5 \mathrm{mg}$, paracetamol $500 \mathrm{mg}$, carbamazepine $200 \mathrm{mg}$ and acetyl salicylic acid (ASA) $100 \mathrm{mg}$ tablets) were available in more than $10 \%$ of the settings surveyed. The overall (pooled) percent availability of $O B$ versions of these essential medicines in all facilities (both public and private) was about 3.6\% (range: $0-31.7 \%)$. Observing the public medicine outlets alone, 39 OB medicines (78\%) were not available in all facilities during the study period. Moreover, except carbamazepine/Tegretol $(n=7)$ and azithromycin/ Zithromax $(n=4)$, the rest drugs were available in only one of the 28 public medicine outlets surveyed. The overall percent availability of $\mathrm{OB}$ medicines in surveyed public sectors was $1.43 \%$. Regarding the private sector, 30 OB medicines $(60 \%)$ were not available at all. Only 6 OB versions of drugs (metformin $500 \mathrm{mg}$, diclofenac $50 \mathrm{mg}$, glibenclamide $5 \mathrm{mg}$, paracetamol $500 \mathrm{mg}$, ASA 100, and carbamazepine $200 \mathrm{mg}$ tabs) were available in more than $10 \%$ of the private facilities surveyed. What is more, the OB versions of drugs like was $46.97 \%$, ranging from $1.7 \%$ (bisoprolol $5 \mathrm{mg}$ and amiodarone $200 \mathrm{mg}$ tabs) to $93.3 \%$ (amoxicillin $500 \mathrm{mg}$ cap). The LPG versions of six drugs (bisoprolol, simvastatin, loperamide, amiodarone, ASA $100 \mathrm{mg}$, and carbamazepine) were not available at all in public facilities and one of which was from the WHO/HAI core drug category. In general, 26 LPG versions (52\%) of the surveyed medicines were available in $50 \%$ or more of the facilities included in the study. Only eight LPG versions were available in $80 \%$ or more of the facilities surveyed. In descending order, amoxicillin $500 \mathrm{mg}$ caps (93.3\%), omeprazole $20 \mathrm{mg}$ cap (90\%), ceftriaxone $1 \mathrm{~g}$ inj. vial (88.3\%), doxycycline $100 \mathrm{mg}$ cap (88.3\%), metformin $500 \mathrm{mg}$ tab (83.3\%), ciprofloxacin $500 \mathrm{mg}$ tab (83.3\%), metronidazole $250 \mathrm{mg}$ cap (83.3\%), and diclofenac $50 \mathrm{mg}$ tab $(80.0 \%)$ were the top eight drugs available during the study. The overall percent availability of LPGs in surveyed public sectors was $42.5 \%$ (hospital $=53.11 \%$ and health center $=37.47 \%$ ) whereas that of the private counterparts were $50.8 \%$ $($ pharmacy $=55.7 \%$ and drug store $=42.83 \%)($ Table 2$)$.

Regarding the source of available drugs, 17 LPGs (34\%) were totally imported. From which, four drugs (diazepam, ceftriaxone, simvastatin and captopril) were among the WHO/HAI core list. Except ceftriaxone $(n=53)$, TTC $(n=34)$ and hydrocortisone $(n=31)$, all other imported drugs (LPG versions) were available in less than $50 \%$ of the surveyed facilities. Two drugs (metronidazole 


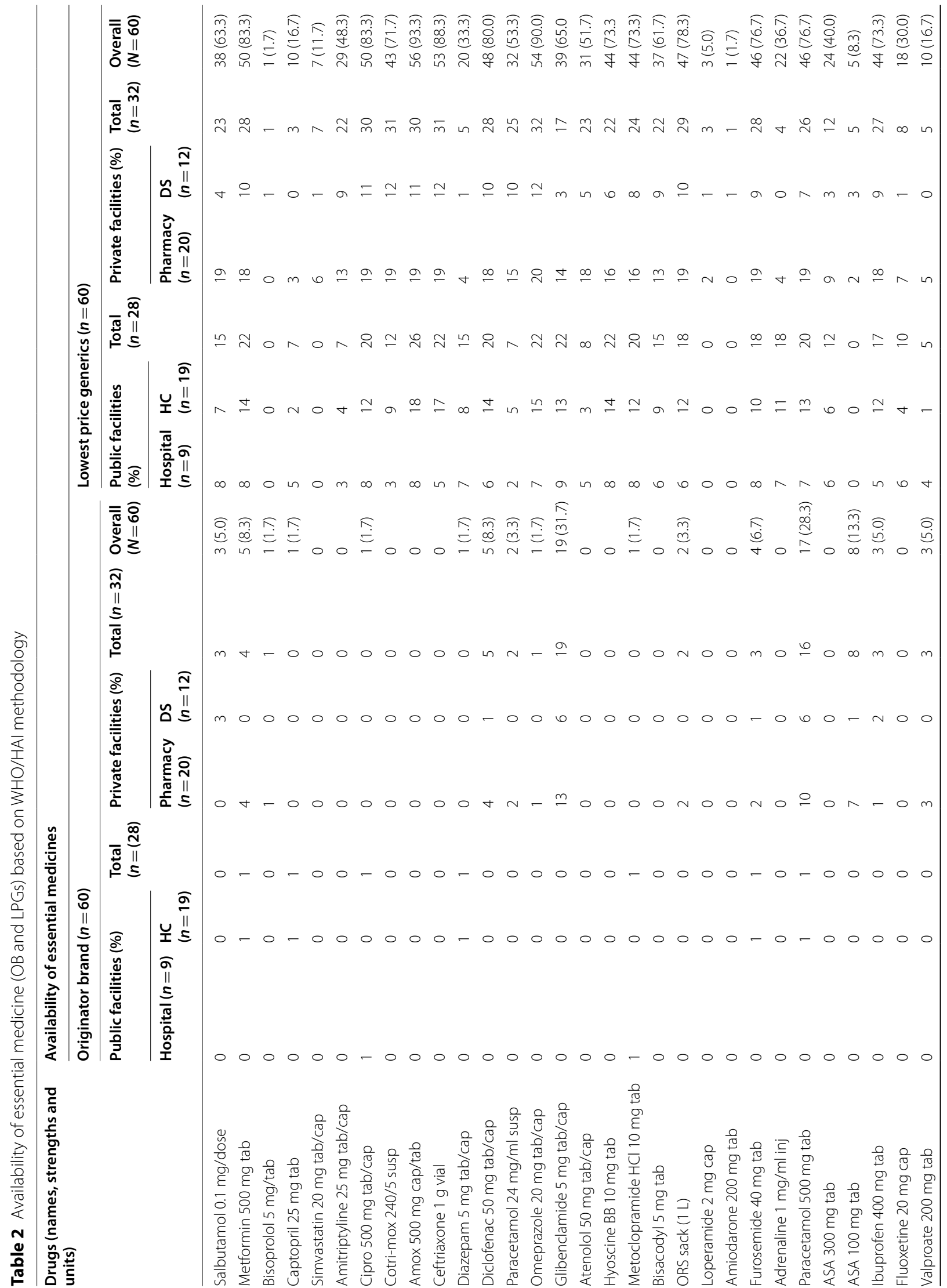




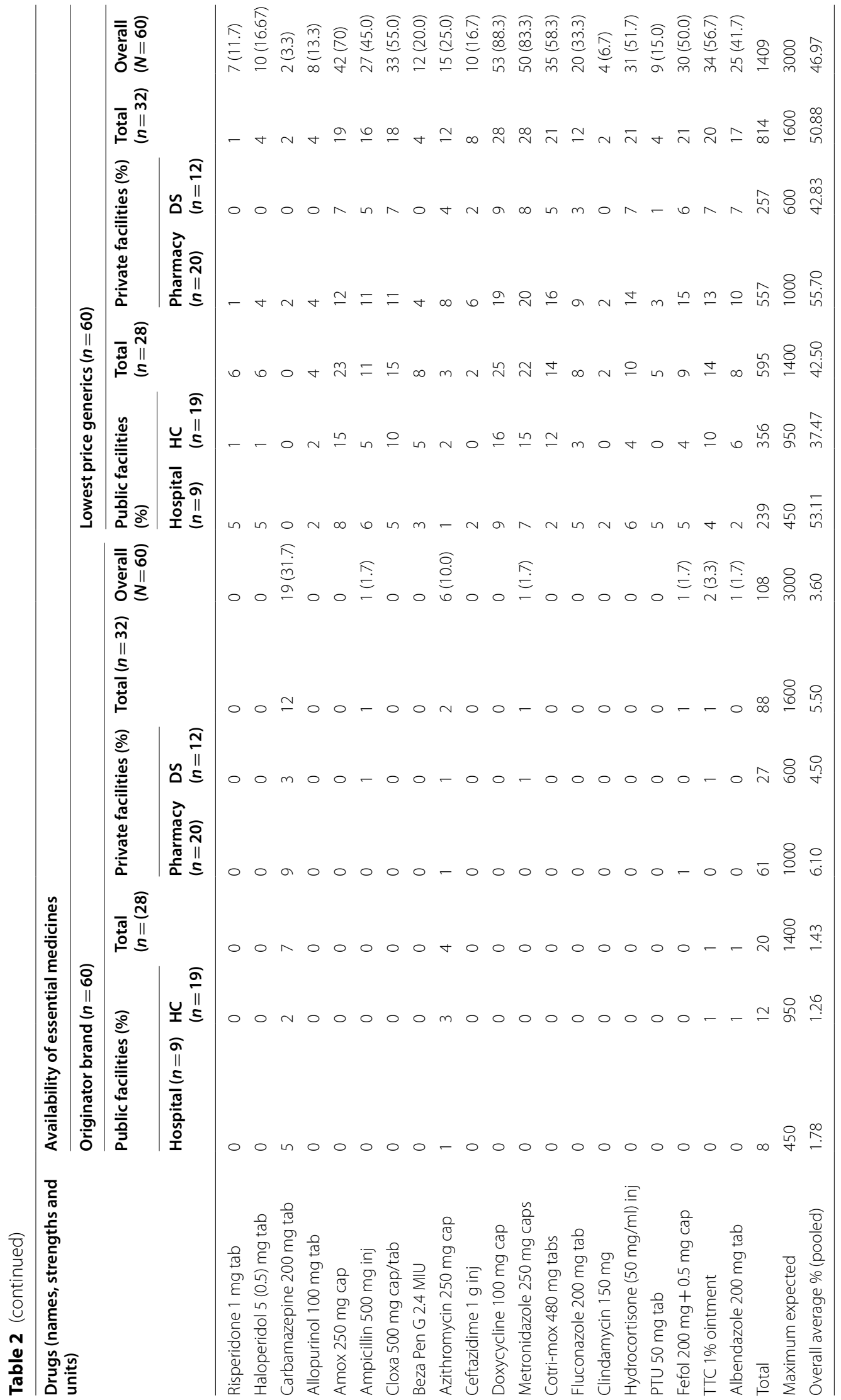


and fluoxetine) were from local source only. The rest 31 drugs were from both sources with certain domination from imported ones (Fig. 1).
Regarding the therapeutic classes, the study included chemotherapeutic agents $(n=17)$, cardiovascular drugs (CVS) $(n=8)$, central nervous system (CNS) drugs

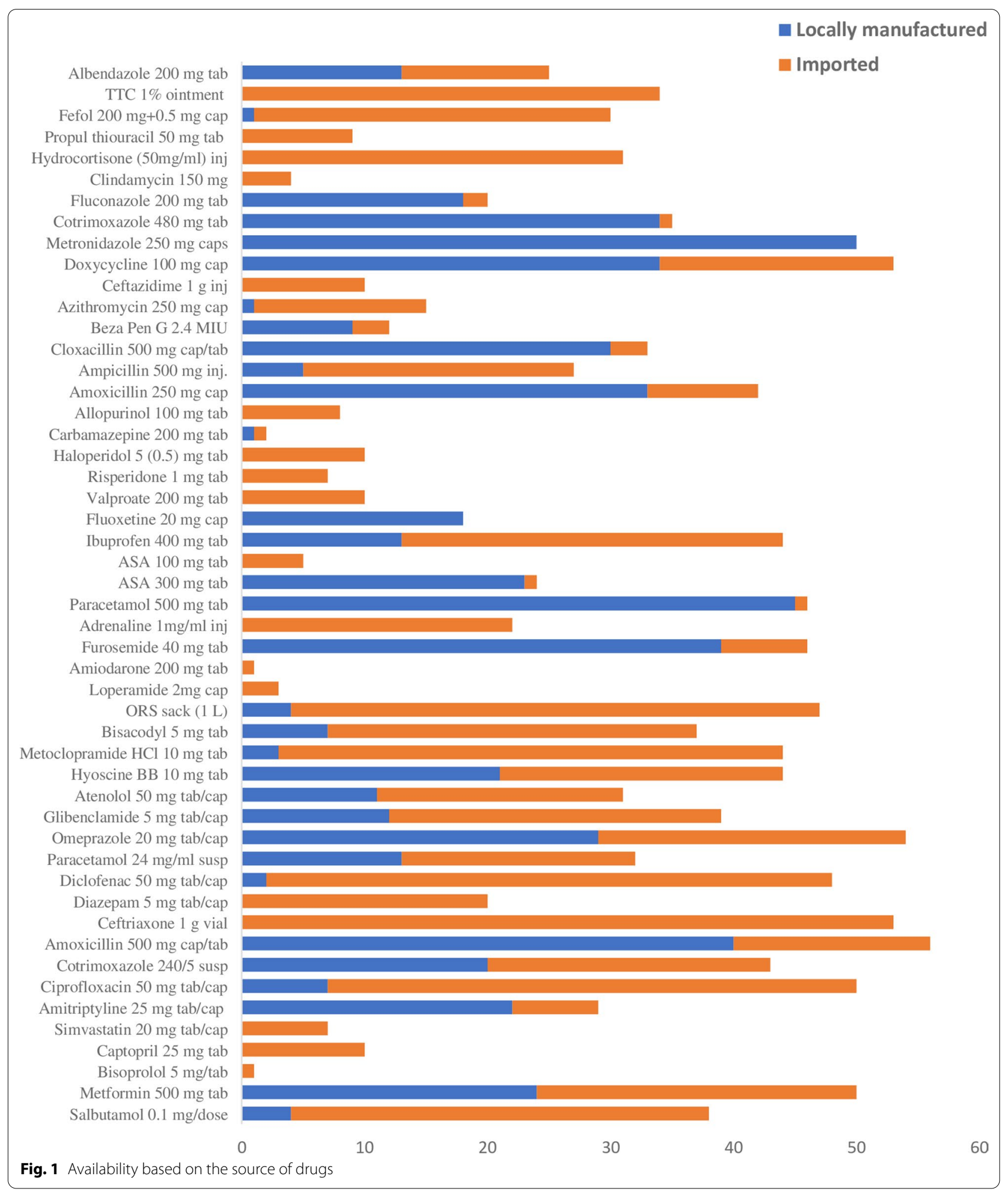


$(n=7)$, gastrointestinal drugs $(n=6)$, non-steroidal anti-inflammatory drugs (NSAIDs) $(n=5)$, respiratory agents $(n=2)$ and two more from miscellaneous agents. Comparing the overall availability, the LPG versions of these drugs were obtained from private settings in almost all therapeutic classes. OB medicines obtained from public facilities were primarily from CNS (40\%) and chemotherapeutic drugs (35\%) whereas those obtained from private counterparts were from NSAIDs (29.5\%) and endocrine agents (26.1\%). Generally, the average percent availability per class indicated that the top three available (for any LPG versions) were chemotherapeutic drugs (public: 53.78\%; private: $68.93 \%$ ), CNS drugs (public: 48.47\%; private: $49.11 \%$ ) and GI agents (public: $48.21 \%$; private: $58.33 \%$ ) (Fig. 2).

Based on the duration of therapeutic regimen, majority of the drugs available in both public and private settings were those agents being used for acute conditions (for less than 2 weeks). The average percent availability of drugs used for acute and chronic conditions was 51.26\% (public: $46.77 \%$; private: $55.75 \%$ ) and $39.23 \%$ (public: 35.53\%; private: $42.93 \%$ ), respectively (Fig. 3).

\section{Cost analysis of essential medicines}

Drugs like adrenaline, ASA 300, and ibuprofen had comparable median buyers' price between public and private medicine outlets. On the other hand, the median buyers' price of drugs in private settings were higher than the public counterparts for $94 \%(n=47)$ of LPGs analyzed. From these, the Mann-Whitney $U$ test indicated that $64 \%(n=32)$ drugs showed statistically significant median price difference between public and private settings $(p<0.05)$ (Table 3$)$. Specifically, the private median prices of LPG versions were more than three times that of the public sector for drugs such as ampicillin, azithromycin, ceftazidime, diazepam, fluconazole, hydrocortisone, metoclopramide and ORS. Likewise, Kruskal-Wallis test indicated that $50 \%$ of drugs showed statistically significant median price difference across facilities (Table 4).

Regarding the WHO/MSH median buyers' price, the MPR indicated that the median prices of drugs in public facilities were more than three times the reference price in 8 LPG versions of essential medicines including atenolol, captopril, fluoxetine, furosemide, cotrimoxazole suspension, paracetamol suspension, salbutamol inhaler, and risperidone tablets. Drugs like metronidazole,

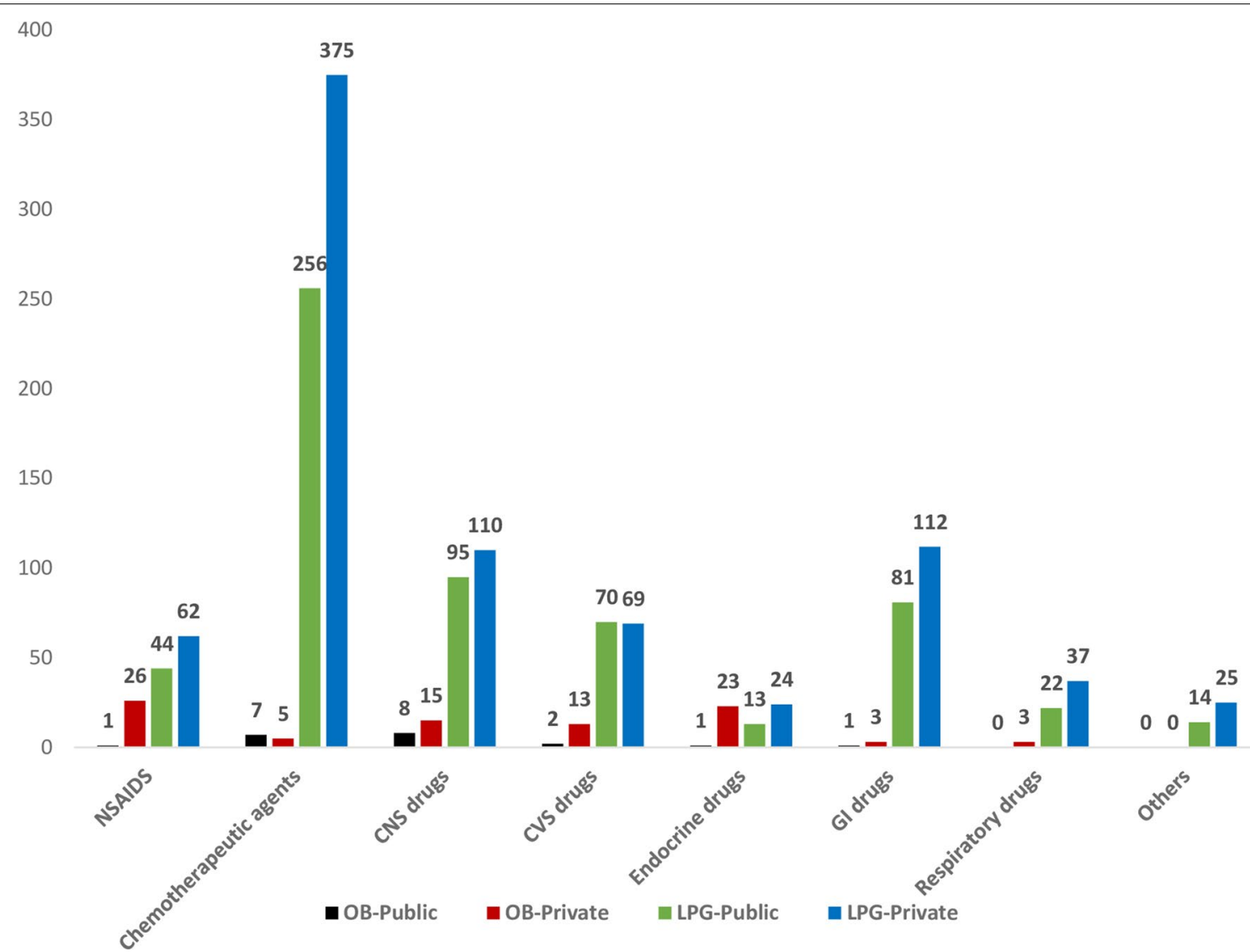

Fig. 2 Availability by therapeutic class of $L P G$ versions of essential medicines 


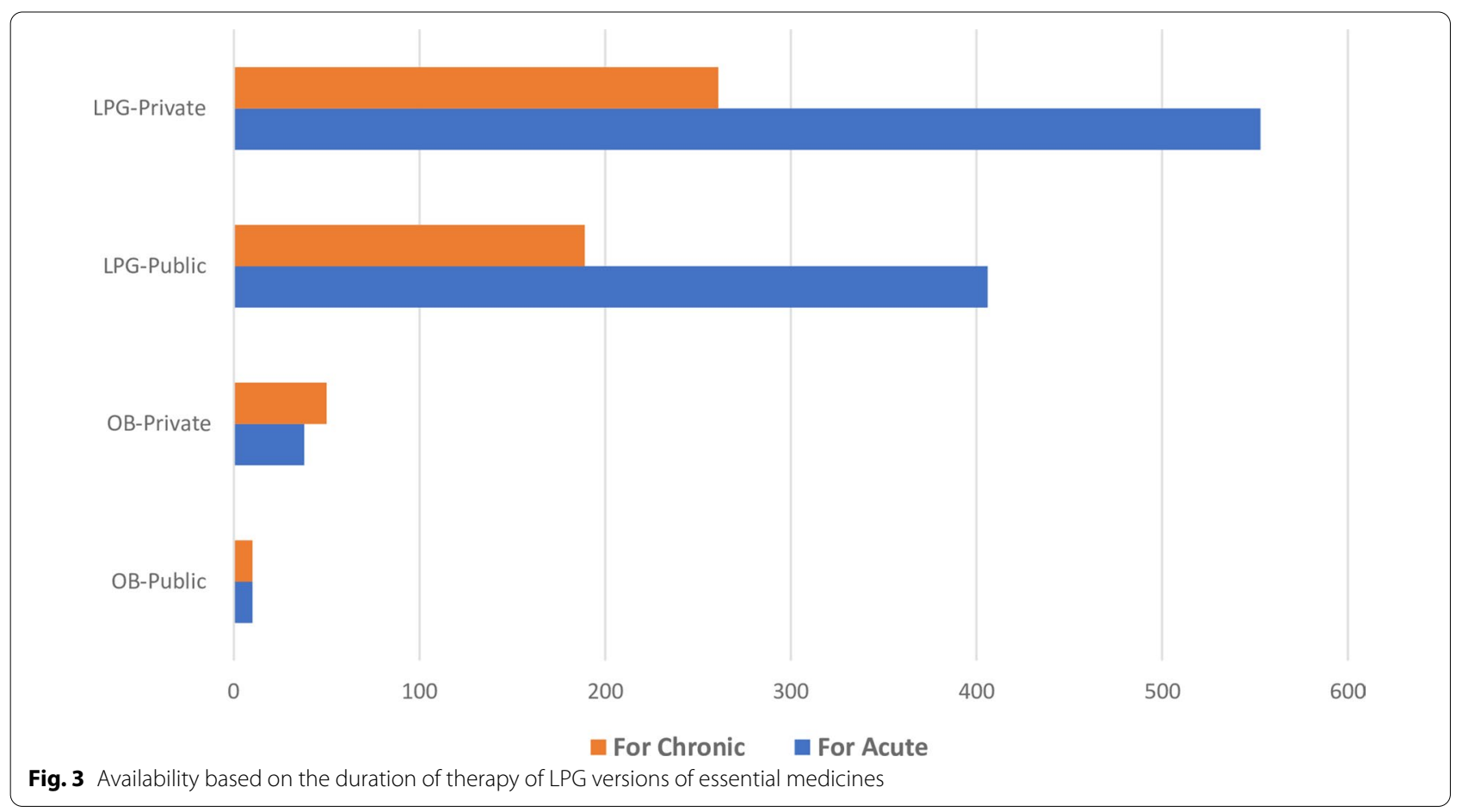

propylthiouracil, ibuprofen, and hyoscine had local buyers' price of more than two times the international median price. Looking at the private sectors, the MPR value indicated that the median buyers' price of drugs were more than four times the international reference price in $30 \%$ of drugs. Overall, drugs with top ten MPR were salbutamol inhaler, cotrimoxazole suspension, paracetamol suspension, loperamide tab, ASA 100, simvastatin, fluoxetine, risperidone, atenolol and furosemide (Table 5).

\section{Affordability of essential medicines}

Majority of the medicines were found to be unaffordable, costing more than one day wage in both private and public facilities. The percentage of unaffordable medicine were 72.09 and 91.84 for public and private facilities, respectively, with $79.17 \%$ of the medicines were unaffordable when both settings are combined. The result of the overall affordability calculation revealed that ceftazidime, risperidone, and ampicillin injection were the top three unaffordable medications requiring 171.33, 73.43 and 58.74 days wage of the lowest paid government employee, respectively. The top three unaffordable medications in the private facilities were ceftazidime, risperidone and valproate requiring 186.01, 95.45 and 62.89 days wage of the lowest paid government employee, respectively. While in the public facilities risperidone takes the lead with 70.91 days wage followed by ceftazidime and valproate with 53.84- and 39.88-days wage, respectively (Table 6).

\section{Discussion}

Access to essential medicines is a universal human right and availability and affordability are the preconditions for it $[21,22]$. In line with the sustainable development goals, WHO has outlined a framework that assists the policy makers to improve access to essential medicine for universal health coverage by 2030 . The four major components of access are rational selection and use of medicines, availability and affordability, sustainable healthcare financing, and reliable supply system of quality products [22-24]. In this regard, essential medicines should be systematically selected using evidence-based approach with due consideration on public health priority, comparative cost-effectiveness, efficacy, safety, and generic versions, among others. The provision of complete healthcare is realized when essential medicines are available in the required quality, quantity, and at all times and in a way that patients can easily afford [22, 23, 25].

However, the availability of essential medicines is still suboptimal in several low-income countries. In particular, the availability of pediatric formulations and key medicines for chronic diseases is still suboptimal even in middle-income countries [26]. As per the global action plan of WHO, the proposed $80 \%$ target for access to essential medicines is the key to attain the overall target of $25 \%$ relative reduction in premature mortality from 
Table 3 Median price of LPG versions of essential medicines (USD) by ownership

\begin{tabular}{|c|c|c|c|c|c|c|c|c|c|}
\hline \multirow{3}{*}{$\begin{array}{l}\text { Name of the drugs } \\
\text { (name, strength and Unit) }\end{array}$} & \multicolumn{8}{|c|}{ Lowest price generics (LPG) } & \multirow[t]{3}{*}{$p$ value } \\
\hline & \multicolumn{3}{|c|}{$\begin{array}{l}\text { Public facilities } \\
\text { Median price, USD }\end{array}$} & \multicolumn{3}{|c|}{$\begin{array}{l}\text { Private facilities (\%) } \\
\text { Median price, USD }\end{array}$} & \multirow[t]{2}{*}{$\begin{array}{l}\text { Mann- } \\
\text { Whitney U }\end{array}$} & \multirow[t]{2}{*}{ Wilcoxon W } & \\
\hline & Median & 25th & 75th & Median & 25th & 75th & & & \\
\hline 1. Salbutamol $0.1 \mathrm{mg} /$ dose & 2.062 & 1.888 & 2.092 & 3.385 & 3.077 & 4.000 & 19.5 & 139.5 & $0.000^{*}$ \\
\hline 2. Metformin $500 \mathrm{mg}$ tab & 0.022 & 0.017 & 0.031 & 0.031 & 0.031 & 0.046 & 87 & 340 & $0.000^{*}$ \\
\hline 3. Bisoprolol $5 \mathrm{mg} / \mathrm{tab}$ & - & - & - & 0.077 & 0.077 & 0.077 & - & - & - \\
\hline 4. Captopril 25 mg tab & 0.031 & 0.019 & 0.031 & 0.046 & 0.025 & - & 6 & 34 & 0.298 \\
\hline 5. Simvastatin $20 \mathrm{mg}$ tab/cap & - & - & - & 0.206 & 0.086 & 0.236 & - & - & - \\
\hline 6. Amitriptyline $25 \mathrm{mg}$ tab/cap & 0.019 & 0.019 & 0.031 & 0.054 & 0.041 & 0.077 & 17 & 45 & $0.002^{*}$ \\
\hline 7. Cipro $50 \mathrm{mg}$ tab/cap & 0.031 & 0.031 & 0.046 & 0.062 & 0.046 & 0.077 & 73.5 & 283.5 & $0.000^{*}$ \\
\hline 8. Cotri-mox 240/5 susp & 0.873 & 0.638 & 0.954 & 0.923 & 0.923 & 1.077 & 126.5 & 204.5 & 0.102 \\
\hline 9. Amox $500 \mathrm{mg} c a p / t a b$ & 0.031 & 0.031 & 0.031 & 0.046 & 0.040 & 0.062 & 75 & 426 & $0.000^{*}$ \\
\hline 10. Ceftriaxone $1 \mathrm{~g}$ vial & 0.615 & 0.546 & 0.769 & 0.769 & 0.615 & 0.800 & 221 & 474 & $0.028^{*}$ \\
\hline 11. Diazepam 5 mg tab/cap & 0.012 & 0.006 & 0.031 & 0.040 & 0.007 & 0.077 & 20.5 & 140.5 & 0.134 \\
\hline 12. Diclofenac 50 mg tab/cap & 0.007 & 0.006 & 0.015 & 0.015 & 0.009 & 0.031 & 127.5 & 337.5 & $0.001^{*}$ \\
\hline 13. Paracetamol $24 \mathrm{mg} / \mathrm{ml}$ susp & 0.462 & 0.308 & 0.985 & 0.923 & 0.769 & 0.923 & 61.5 & 89.5 & 0.222 \\
\hline 14. Omeprazole 20 mg tab/cap & 0.016 & 0.015 & 0.019 & 0.031 & 0.022 & 0.031 & 105 & 358 & $0.000^{*}$ \\
\hline 15. Glibenclamide 5 mg tab/cap & 0.009 & 0.008 & 0.031 & 0.022 & 0.017 & 0.042 & 87 & 340 & $0.004^{*}$ \\
\hline 16. Atenolol $50 \mathrm{mg} \mathrm{tab/cap}$ & 0.023 & 0.015 & 0.031 & 0.031 & 0.028 & 0.046 & 46.5 & 82.5 & $0.035^{*}$ \\
\hline 17. Hyoscine BB $10 \mathrm{mg}$ tab & 0.105 & 0.092 & 0.108 & 0.111 & 0.099 & 0.123 & 167.5 & 443.5 & $0.032^{*}$ \\
\hline 18. Metoclopramide $\mathrm{HCl} 10 \mathrm{mg}$ tab & 0.009 & 0.006 & 0.015 & 0.031 & 0.015 & 0.031 & 85 & 295 & $0.000^{*}$ \\
\hline 19. Bisacodyl 5 mg tab & 0.023 & 0.021 & 0.031 & 0.062 & 0.031 & 0.077 & 27.5 & 147.5 & $0.000^{*}$ \\
\hline 20. ORS sack (1 L) & 0.080 & 0.000 & 0.154 & 0.308 & 0.215 & 0.308 & 51.5 & 241.5 & $0.000^{*}$ \\
\hline 21. Loperamide 2 mg cap & - & - & - & 0.292 & 0.092 & - & - & - & - \\
\hline 22. Amiodarone $200 \mathrm{mg}$ tab & - & - & - & - & - & - & - & - & - \\
\hline 23. Furosemide $40 \mathrm{mg}$ tab & 0.020 & 0.012 & 0.030 & 0.031 & 0.031 & 0.041 & 81.5 & 252.5 & $0.000^{*}$ \\
\hline 24. Adrenaline $1 \mathrm{mg} / \mathrm{ml}$ inj & 0.138 & 0.113 & 0.162 & 0.138 & 0.092 & 0.623 & 34 & 44 & 0.863 \\
\hline 25. Paracetamol $500 \mathrm{mg}$ tab & 0.006 & 0.006 & 0.015 & 0.015 & 0.015 & 0.019 & 90 & 300 & $0.000^{*}$ \\
\hline 26. ASA $300 \mathrm{mg}$ tab & 0.015 & 0.014 & 0.031 & 0.015 & 0.010 & 0.015 & 53 & 131 & 0.258 \\
\hline 27. ASA $100 \mathrm{mg}$ tab & - & - & - & 0.092 & 0.042 & 0.231 & - & - & - \\
\hline 28. Ibuprofen 400 mg tab & 0.031 & 0.025 & 0.031 & 0.031 & 0.031 & 0.031 & 137.5 & 290.5 & $0.003^{*}$ \\
\hline 29. Fluoxetine 20 mg cap & 0.032 & 0.031 & 0.035 & 0.095 & 0.081 & 0.119 & 9 & 64 & $0.006^{*}$ \\
\hline 30. Valproate $200 \mathrm{mg}$ tab & 0.078 & 0.051 & 0.092 & 0.123 & 0.104 & 0.154 & 1 & 16 & $0.015^{*}$ \\
\hline 31. Risperidone $1 \mathrm{mg}$ tab & 0.208 & 0.044 & 0.222 & 0.280 & 0.280 & 0.280 & 0 & 21 & 0.134 \\
\hline 32. Haloperidol $5(0.5) \mathrm{mg}$ tab & 0.023 & 0.018 & 0.031 & 0.062 & 0.034 & - & 0 & 21 & $0.019^{*}$ \\
\hline 33. Carbamazepine $200 \mathrm{mg}$ tab & - & - & - & 0.088 & 0.062 & - & - & - & - \\
\hline 34. Allopurinol $100 \mathrm{mg} \mathrm{tab}$ & 0.032 & 0.031 & 0.034 & 0.060 & 0.036 & 0.158 & 1 & 11 & $0.037^{*}$ \\
\hline 35. Amox 250 mg cap & 0.015 & 0.015 & 0.029 & 0.031 & 0.031 & 0.062 & 67.5 & 367.5 & $0.000^{*}$ \\
\hline 36. Ampicillin $500 \mathrm{mg}$ inj & 0.154 & 0.123 & 0.246 & 0.462 & 0.308 & 0.615 & 30 & 96 & $0.004^{*}$ \\
\hline 37. Cloxa $500 \mathrm{mg}$ cap/tab & 0.045 & 0.031 & 0.051 & 0.062 & 0.046 & 0.082 & 45 & 136 & $0.006^{*}$ \\
\hline 38. Beza Pen G 2.4 MIU & 0.280 & 0.223 & 0.308 & 0.462 & 0.308 & 1.077 & 5 & 41 & 0.053 \\
\hline 39. Azithromycin $250 \mathrm{mg}$ cap & 0.123 & 0.123 & 0.123 & 0.462 & 0.279 & 0.590 & 6 & 12 & 0.081 \\
\hline 40. Ceftazidime $1 \mathrm{~g}$ inj & 0.846 & 0.831 & & 2.923 & 2.592 & 3.077 & 0.5 & 3.5 & $0.047^{*}$ \\
\hline 41. Doxycycline 100 mg cap & 0.019 & 0.017 & 0.026 & 0.031 & 0.031 & 0.046 & 75.5 & 400.5 & $0.000^{*}$ \\
\hline 42. Metronidazole $250 \mathrm{mg}$ caps & 0.015 & 0.012 & 0.028 & 0.017 & 0.015 & 0.031 & 209.5 & 462.5 & $0.048^{*}$ \\
\hline 43. Cotri-mox $480 \mathrm{mg}$ tabs & 0.015 & 0.012 & 0.016 & 0.031 & 0.015 & 0.031 & 66.5 & 171.5 & $0.005^{*}$ \\
\hline 44. Fluconazole $200 \mathrm{mg}$ tab & 0.037 & 0.032 & 0.039 & 0.169 & 0.108 & 0.215 & 6 & 42 & $0.001^{*}$ \\
\hline 45. Clindamycin $150 \mathrm{mg}$ & 0.129 & 0.128 & - & 0.097 & 0.092 & - & 0 & 3 & 0.121 \\
\hline 46. Hydrocortisone $(50 \mathrm{mg} / \mathrm{ml})$ inj & 0.492 & 0.492 & 0.869 & 1.846 & 1.308 & 2.154 & 10.5 & 65.5 & $0.000^{*}$ \\
\hline 47. PTU $50 \mathrm{mg}$ tab & 0.145 & 0.106 & 0.149 & 0.269 & 0.132 & 0.294 & 4 & 19 & 0.140 \\
\hline
\end{tabular}


Table 3 (continued)

\begin{tabular}{|c|c|c|c|c|c|c|c|c|c|}
\hline \multirow{3}{*}{$\begin{array}{l}\text { Name of the drugs } \\
\text { (name, strength and Unit) }\end{array}$} & \multicolumn{8}{|c|}{ Lowest price generics (LPG) } & \multirow[t]{3}{*}{$p$ value } \\
\hline & \multicolumn{3}{|c|}{$\begin{array}{l}\text { Public facilities } \\
\text { Median price, USD }\end{array}$} & \multicolumn{3}{|c|}{$\begin{array}{l}\text { Private facilities (\%) } \\
\text { Median price, USD }\end{array}$} & \multirow[t]{2}{*}{$\begin{array}{l}\text { Mann- } \\
\text { Whitney U }\end{array}$} & \multirow[t]{2}{*}{ Wilcoxon W } & \\
\hline & Median & 25th & 75th & Median & 25 th & 75th & & & \\
\hline 48. Fefol $200 \mathrm{mg}+0.5 \mathrm{mg}$ cap & 0.028 & 0.016 & 0.031 & 0.055 & 0.046 & 0.062 & 8 & 53 & $0.000^{*}$ \\
\hline 49. TTC $1 \%$ ointment & 0.185 & 0.154 & 0.308 & 0.308 & 0.308 & 0.308 & 50.5 & 155.5 & $0.001^{*}$ \\
\hline 50. Albendazole $200 \mathrm{mg}$ tab & 0.031 & 0.031 & 0.154 & 0.077 & 0.031 & 0.154 & 46 & 74 & 0.388 \\
\hline
\end{tabular}

Wilcoxon-Mann-Whitney $U$ test for two independent groups (public and private settings) with skewed price distribution

chronic non-communicable diseases (NCDs) by 2025 [27]. Besides, improving the availability and affordability of essential medicines is likely to enhance their use and help towards in achieving WHO targets of $50 \%$ use of key medicines by 2025 [28].

In this regard, this study has addressed the availability, price and affordability of 50 essential medicines in public and private health facilities of eastern Ethiopia. Generally, nearly half of OB medicines, $42.85 \%$ OBs from WHO/HAI core drugs, were totally absent in all health facilities included in the survey. The overall availability of OB medicines was lower in public facilities. Besides, nearly half (52\%) of surveyed essential medicines were available in only $50 \%$ or more of the facilities studied. Only eight LPG versions (16.0\%) were available in $80 \%$ or so of the facilities surveyed. The overall availability of LPG versions was higher in private drug retail outlets. Except ceftriaxone and hydrocortisone, all imported LPG versions were available in less than $50 \%$ of the facilities included. Chemotherapeutic agents were the most commonly available class in both public and private settings. The availability index for drugs for chronic diseases was lower than that used for acute conditions.

The median buyers' prices for 94\% LPG versions were significantly higher in private drug retail outlets. Moreover, the private median price of LPGs were more than three times that of the public sector for $16 \%$ of drugs. The MPR value indicated that median price of LPGs in the private sector was more than four times the IRP in $30 \%$ of drugs. In public sector, about $16 \%$ of LPGs had a median price of more than three times than that of IRP. With reference to the lowest paid government employee, majority of LPG medicines were found unaffordable, costing more than one day wage in both public and private facilities. Generally, four out of five essential medicines were found unaffordable in Ethiopian healthcare settings with the worst price escalation being observed in private settings (nine drugs out of ten essential medicines). In low-income countries like Ethiopia, low availability with high buyers' price and low affordability vividly reflects a failure of implementing national drug policy on essential medicines.

Unlike this study, the availability of OBs exceeded the WHO target of $80 \%$ and found affordable in Qatar public health facilities, although $30 \%$ of surveyed medicines were beyond the acceptable threshold of 4.0 in private sector [29]. Compared with this study, study conducted in the northern Ethiopia indicated that there was lower overall availability (34.1\%) but better affordability of LPGs $30 \%$ and $50 \%$ of LPGs demanded more than a single daily wages to purchase these drugs in public and private sectors, respectively [30]. In Jordan, much better availability of LPGs was observed in both public (72\%) and private $(76 \%)$ sectors for chronic diseases and the prices of medicines in public sectors were generally affordable but not in private settings [31]. Likewise, in upper-middle income countries like Malaysia, the affordability of all generic versions of essential medicines was below 2-day wages of the lowest paid government employees in the public sector [32].

In our study, eight drugs (16.0\%) met the WHO target of $80 \%$. It was in trajectory with the study in which $15.2 \%$ and $18.9 \%$ of LPGs met WHO target in the public and private sectors of low-income countries, respectively. This value was 7 to $8 \%$ higher in lower-middle income countries [33]. Besides, a study conducted in Tanzania and central Ethiopia indicated that locally produced products had greater mean availability $(48 \%)$ than that of imported ones (19\%) [34] indicating the need of more local manufacturing plants for better access of essential medicines.

In a study conducted on six low-and middle-income countries, less than $10 \%$ surveyed medicines were available in public sector in four of the countries surveyed [35]. Unlike high-income countries, low- and middleincome countries usually have poor regulation of pharmaceutical markets and often lack feasible purchasing and pricing strategies [36]. Country specific studies indicated that better availability and more affordable generic versions were reported from Rwanda [37] and Nepal 


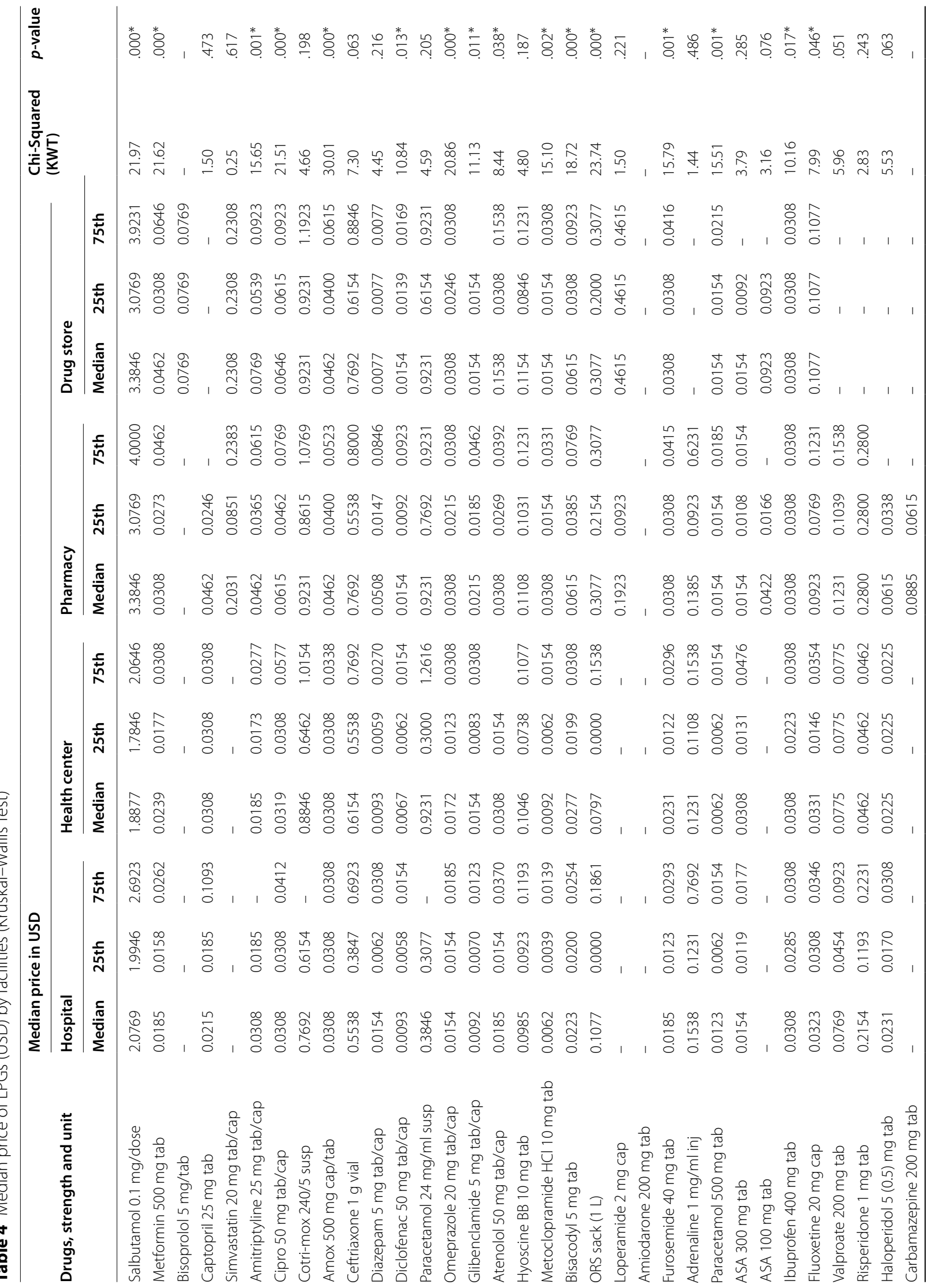




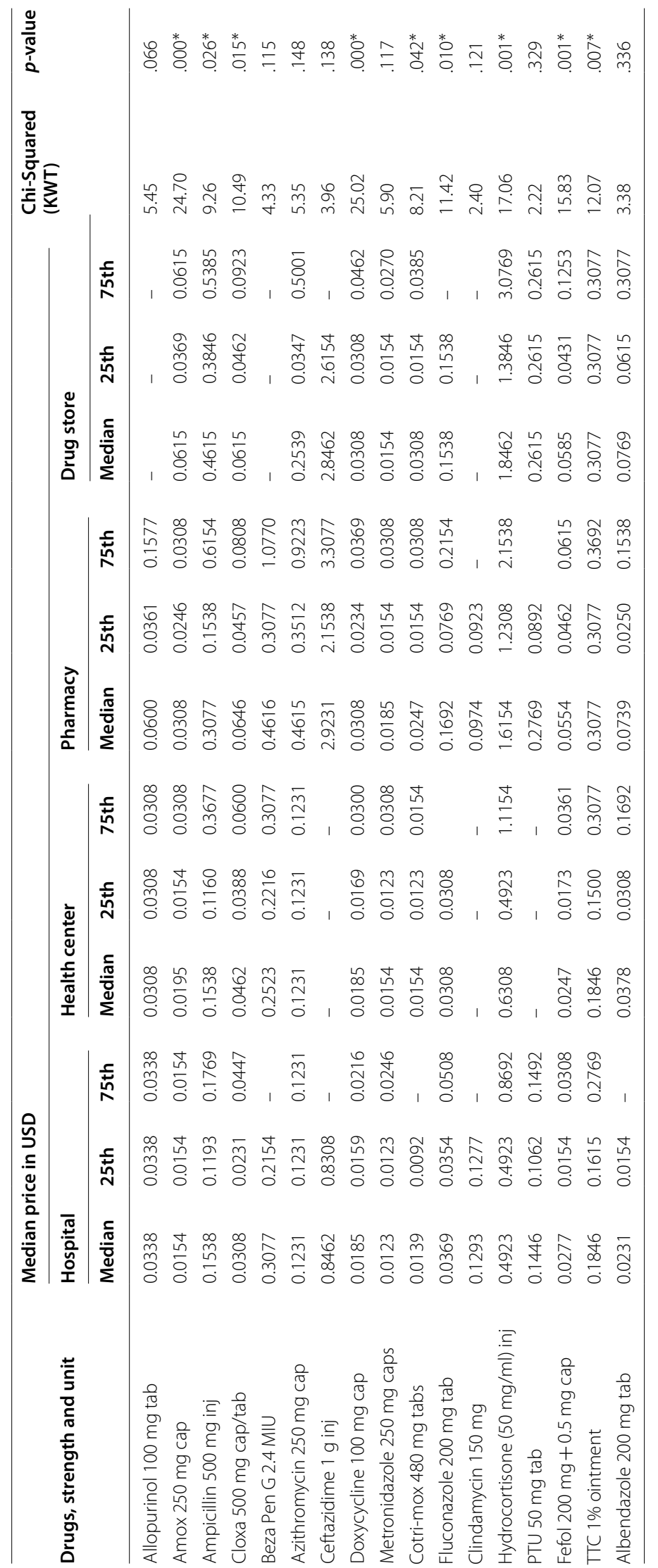


Table 5 (continued)

\begin{tabular}{|c|c|c|c|c|c|c|c|c|}
\hline \multirow[t]{2}{*}{ Name of the drugs } & \multicolumn{7}{|c|}{ Lowest price generics (LPG) } & \multirow{2}{*}{$\begin{array}{l}\text { Private } \\
\text { to public } \\
\text { ratio }\end{array}$} \\
\hline & $\begin{array}{l}\text { Overall } \\
\text { Median price } \\
\text { (USD) }\end{array}$ & 25th & 75th & $\begin{array}{l}\text { WHO/MSH buyers' } \\
\text { median price (USD) }\end{array}$ & $\begin{array}{l}\text { MPR } \\
\text { for public } \\
\text { facilities }\end{array}$ & $\begin{array}{l}\text { MPR for } \\
\text { private } \\
\text { facilities }\end{array}$ & Overall MPR & \\
\hline Simvastatin 20 mg tab/cap & 0.2062 & 0.0862 & 0.2357 & 0.0163 & - & 12.64 & 12.65 & - \\
\hline TTC 1\% ointment & 0.3077 & 0.1846 & 0.3077 & 0.1294 & 1.43 & 2.38 & 2.38 & 1.66 \\
\hline Valproate 200 mg tab & 0.0923 & 0.0735 & 0.1308 & 0.1755 & 0.44 & 0.70 & 0.53 & 1.58 \\
\hline
\end{tabular}

[38]. Relatively higher availability of OBs in both public (6.8\%) and private $(55.0 \%)$ facilities were also observed in Pakistan whereas the availability of generic versions was lower in public (35.3\%) and private (20.3\%) facilities [39]. In a study conducted in China, higher availability of pediatric OBs were observed in public (7.5\%) and private (8.9\%) sectors although the overall availability of generic versions in both public (34.2\%) and private (29.4\%) sectors were by far lower but more affordable compared to our study [40]. What is more, in the primary care settings of Vietnam, the availability of essential medicines was higher $(56.4 \%)$ than our study. Likewise, the study conducted in eleven countries of the Asian Pacific region demonstrated that there was slightly higher availability (56.7\%) of generic versions of essential medicine in the private sector though it was found lower $(35.5 \%)$ in the public sector [41]. In the upper middle-income and high income-countries, the availability of OBs and LPGs was by far higher in both public and private sectors with less price variation and more affordability compared to our study [42-45]

Regarding chronic diseases in particular, a significant proportion of patients in low- and middle-income countries do not have access (low availability and/or low affordability) to generic versions of essential medicines for the treatment of hypertension [46], diabetes [47-49], chronic respiratory diseases including bronchial asthma [27], diabetes and hypertension combined [50], several non-specific NCDs [51-53]. Multilevel analysis also indicated that the availability and affordability of essential diabetes medicines were significantly associated with their use [47]. Likewise, a study conducted in China indicated that high cost medications were more likely to be prescribed than lower cost alternatives and only one-third of facilities stocked high value (essential) medicines [54]. To this end, medicines take a large proportion of household expenditure on health in low-and middle-income countries. According to WHO survey, up to $9.5 \%$ of the total expenditure was spent on medicines and is almost three times higher than the one spent in high-income countries [21, 22, 55]. Inadequate healthcare financing and inefficient and unreliable supply system is attributable to high out-of-pocket expenditure in such resource poor settings. The PURE study also indicated that secondary prevention medicines for cardiovascular diseases were found unavailable and unaffordable in large proportion of customers in low- and middleincome countries [28].

With regard to AWaRe (Access, Watch and Reserve) classification of antibiotics, there has been a declining trend of at least $60 \%$ total consumption of antibiotics (WHO-national level target) in the access category from $76 \%$ in 2000 to $55 \%$ in 2015 . Without policy intervention affecting the availability of such essential antibiotics, it is difficult to attain at least $60 \%$ consumption of antibiotics from 'Access' category by 2023 [56]. In our study, all the included essential antibiotics were from both Access and Watch categories with the former accounting nearly twothirds of the total agents.

Even in countries where there is drug pricing information, the availability of medicines in public sectors is about one-third while that of the private sector is about two-thirds, and the buyers' prices for LPGs vary from 2.5 to 6.5 MPRs in these two sectors [21]. In this regard, a multitude of strategies including managerial, regulatory, economic, and educational approaches shall be devised to increase the access of essential medicines in the public sector [21, 35, 41, 57]. Economic strategies including competitive or pooled procurement policies for multisource products, price negotiation for sole source products, reducing taxes and tariffs and regulating mark-ups, provision of community-based health insurance, and sustainable health care financing shall be taken as the prior agenda for Ethiopia to address all segments of the population. In addition, regulation of the pharmaceutical market, strict implementation of generic procurement policies, efficient and evidence-based procurement, provision of vivid pricing and procurement information, as well as installation of local manufacturing plants shall also be considered to increase the access of essential medicines.

\section{Strength and limitations}

Using validated WHO/HAI methodology allows for the measurement of medicine availability and prices in a 
Table 5 Overall median price, median price ratios (MPR) and affordability of LPGs based on WHO/MSH reference guide (buyers' price)

\begin{tabular}{|c|c|c|c|c|c|c|c|c|}
\hline \multirow[t]{2}{*}{ Name of the drugs } & \multicolumn{7}{|c|}{ Lowest price generics (LPG) } & \multirow{2}{*}{$\begin{array}{l}\text { Private } \\
\text { to public } \\
\text { ratio }\end{array}$} \\
\hline & $\begin{array}{l}\text { Overall } \\
\text { Median price } \\
\text { (USD) }\end{array}$ & 25th & 75th & $\begin{array}{l}\text { WHO/MSH buyers' } \\
\text { median price (USD) }\end{array}$ & $\begin{array}{l}\text { MPR } \\
\text { for public } \\
\text { facilities }\end{array}$ & $\begin{array}{l}\text { MPR for } \\
\text { private } \\
\text { facilities }\end{array}$ & Overall MPR & \\
\hline Adrenaline $1 \mathrm{mg} / \mathrm{ml}$ inj & 0.1385 & 0.1062 & 0.1846 & 0.1926 & 0.72 & 0.72 & 0.72 & 1.00 \\
\hline Albendazole 200 mg tab & 0.0615 & 0.0308 & 0.1538 & 0.0328 & 0.95 & 2.35 & 1.88 & 2.48 \\
\hline Allopurinol 100 mg tab & 0.0338 & 0.0316 & 0.0685 & - & - & - & - & 1.88 \\
\hline Amiodarone 200 mg tab & - & - & - & - & - & - & - & - \\
\hline Amitriptyline 25 mg tab/cap & 0.0462 & 0.0308 & 0.0739 & 0.0281 & 0.68 & 1.92 & 1.64 & 2.84 \\
\hline Amox 250 mg cap & 0.0246 & 0.0154 & 0.0308 & 0.0227 & 0.66 & 1.37 & 1.08 & 2.07 \\
\hline Amox 500 mg cap/tab & 0.0369 & 0.0308 & 0.0462 & 0.0299 & 1.04 & 1.54 & 1.23 & 1.48 \\
\hline Ampicillin 500 mg inj & 0.3077 & 0.1538 & 0.4615 & 0.3696 & 0.42 & 1.25 & 0.83 & 3.00 \\
\hline ASA 100 mg tab & 0.0923 & 0.0422 & 0.2308 & 0.0062 & - & 14.84 & 14.89 & - \\
\hline ASA 300 mg tab & 0.0154 & 0.0123 & 0.0293 & 0.0391 & 0.38 & 0.38 & 0.39 & 1.00 \\
\hline Atenolol 50 mg tab/cap & 0.0308 & 0.0246 & 0.0462 & 0.0059 & 3.90 & 5.25 & 5.22 & 1.35 \\
\hline Azithromycin 250 mg cap & 0.3591 & 0.1231 & 0.5129 & 0.198 & 0.62 & 2.33 & 1.81 & 3.76 \\
\hline Beza Pen G 2.4 MIU & 0.3077 & 0.2477 & 0.3308 & - & - & - & - & 1.65 \\
\hline Bisacodyl 5 mg tab & 0.0308 & 0.0239 & 0.0615 & 0.0147 & 1.56 & 4.22 & 2.10 & 2.70 \\
\hline Bisoprolol 5 mg/tab & - & - & - & 0.0462 & - & 1.67 & 1.67 & - \\
\hline Captopril 25 mg tab & 0.0308 & 0.0208 & 0.0654 & 0.0076 & 4.08 & 6.05 & 4.05 & 1.48 \\
\hline Carbamazepine 200 mg tab & 0.0885 & 0.0461 & 0.0922 & 0.0202 & - & 4.36 & 4.38 & - \\
\hline Ceftazidime $1 \mathrm{~g}$ inj & 2.6923 & 0.8615 & 3.0769 & 1.77 & 0.48 & 1.65 & 1.52 & 3.46 \\
\hline Ceftriaxone $1 \mathrm{~g}$ vial & 0.6462 & 0.5538 & 0.7692 & 0.4251 & 1.45 & 1.81 & 1.52 & 1.25 \\
\hline Cipro 500 mg tab/cap & 0.0615 & 0.0308 & 0.0685 & 0.0269 & 1.15 & 2.30 & 2.29 & 2.00 \\
\hline Clindamycin 150 mg & 0.1151 & 0.0949 & 0.1300 & 0.173 & 0.75 & 0.56 & 0.67 & 0.75 \\
\hline Cloxa 500 mg cap/tab & 0.0462 & 0.0438 & 0.0708 & 0.0566 & 0.80 & 1.10 & 0.82 & 1.38 \\
\hline Cotri-mox 240/5 susp & 0.9231 & 0.8615 & 1.0769 & 0.0042 & 207.86 & 219.76 & 219.79 & 1.06 \\
\hline Cotri-mox $480 \mathrm{mg}$ tabs & 0.0154 & 0.0154 & 0.0308 & 0.0116 & 1.29 & 2.67 & 1.33 & 2.07 \\
\hline Diazepam 5 mg tab/cap & 0.0139 & 0.0062 & 0.0366 & 0.0189 & 0.63 & 2.12 & 0.73 & 3.33 \\
\hline Diclofenac 50 mg tab/cap & 0.0154 & 0.0079 & 0.0154 & 0.0127 & 0.55 & 1.18 & 1.21 & 2.14 \\
\hline Doxycycline 100 mg cap & 0.0308 & 0.0185 & 0.0308 & 0.0192 & 0.99 & 1.61 & 1.60 & 1.63 \\
\hline Fefol 200 mg + 0.5 mg cap & 0.0462 & 0.0308 & 0.0615 & 0.0314 & 0.89 & 1.75 & 1.47 & 1.96 \\
\hline Fluconazole 200 mg tab & 0.0354 & 0.0308 & 0.0939 & 0.0698 & 0.53 & 2.42 & 0.51 & 4.57 \\
\hline Fluoxetine 20 mg cap & 0.0769 & 0.0369 & 0.1692 & 0.0103 & 3.11 & 9.22 & 7.47 & 2.97 \\
\hline Furosemide $40 \mathrm{mg}$ tab & 0.0308 & 0.0208 & 0.0308 & 0.0062 & 3.23 & 5.00 & 4.97 & 1.55 \\
\hline Glibenclamide 5 mg tab/cap & 0.0185 & 0.0092 & 0.0308 & 0.0053 & 1.70 & 4.15 & 3.49 & 2.44 \\
\hline Haloperidol 5 (0.5) mg tab & 0.0308 & 0.0205 & 0.0477 & 0.0572 & 0.40 & 1.08 & 0.54 & 2.70 \\
\hline Hydrocortisone $(50 \mathrm{mg} / \mathrm{ml})$ inj & 1.3846 & 0.7692 & 2.1538 & 0.520 & 0.95 & 3.55 & 2.66 & 3.75 \\
\hline Hyoscine BB 10 mg tab & 0.1077 & 0.0923 & 0.1231 & 0.0421 & 2.49 & 2.64 & 2.56 & 1.06 \\
\hline Ibuprofen 400 mg tab & 0.0308 & 0.0308 & 0.0308 & 0.0132 & 2.35 & 2.35 & 2.33 & 1.00 \\
\hline Loperamide 2 mg cap & 0.2923 & 0.0923 & 0.4615 & 0.0103 & - & 28.35 & 28.38 & - \\
\hline Metformin 500 mg tab & 0.0308 & 0.0215 & 0.0392 & 0.0162 & 1.36 & 1.91 & 1.90 & 1.41 \\
\hline Metoclopramide $\mathrm{HCl} 10$ mg tab & 0.0154 & 0.0092 & 0.0308 & 0.0081 & 1.11 & 3.83 & 1.90 & 3.44 \\
\hline Metronidazole 250 mg caps & 0.0154 & 0.0154 & 0.0308 & 0.0067 & 2.24 & 2.54 & 2.30 & 1.13 \\
\hline Omeprazole 20 mg tab/cap & 0.0215 & 0.0171 & 0.0308 & 0.0154 & 1.04 & 2.01 & 1.40 & 1.94 \\
\hline ORS sack (1 L) & 0.2154 & 0.0923 & 0.3077 & 0.0561 & 1.43 & 5.49 & 3.84 & 3.85 \\
\hline Paracetamol 24 mg/ml susp & 0.9231 & 0.6308 & 0.9231 & 0.0064 & 72.19 & 144.22 & 144.23 & 2.00 \\
\hline Paracetamol 500 mg tab & 0.0154 & 0.0069 & 0.0185 & 0.0058 & 1.03 & 2.59 & 2.66 & 2.50 \\
\hline PTU 50 mg tab & 0.1446 & 0.1139 & 0.2692 & 0.0718 & 2.02 & 3.75 & 2.01 & 1.86 \\
\hline Salbutamol $0.1 \mathrm{mg} /$ dose & 3.0769 & 2.0615 & 3.6923 & 0.0058 & 355.52 & 583.62 & 530.50 & 1.64 \\
\hline Risperidone 1 mg tab & 0.2154 & 0.0462 & 0.2246 & 0.0375 & 5.55 & 7.47 & 5.74 & 1.35 \\
\hline
\end{tabular}




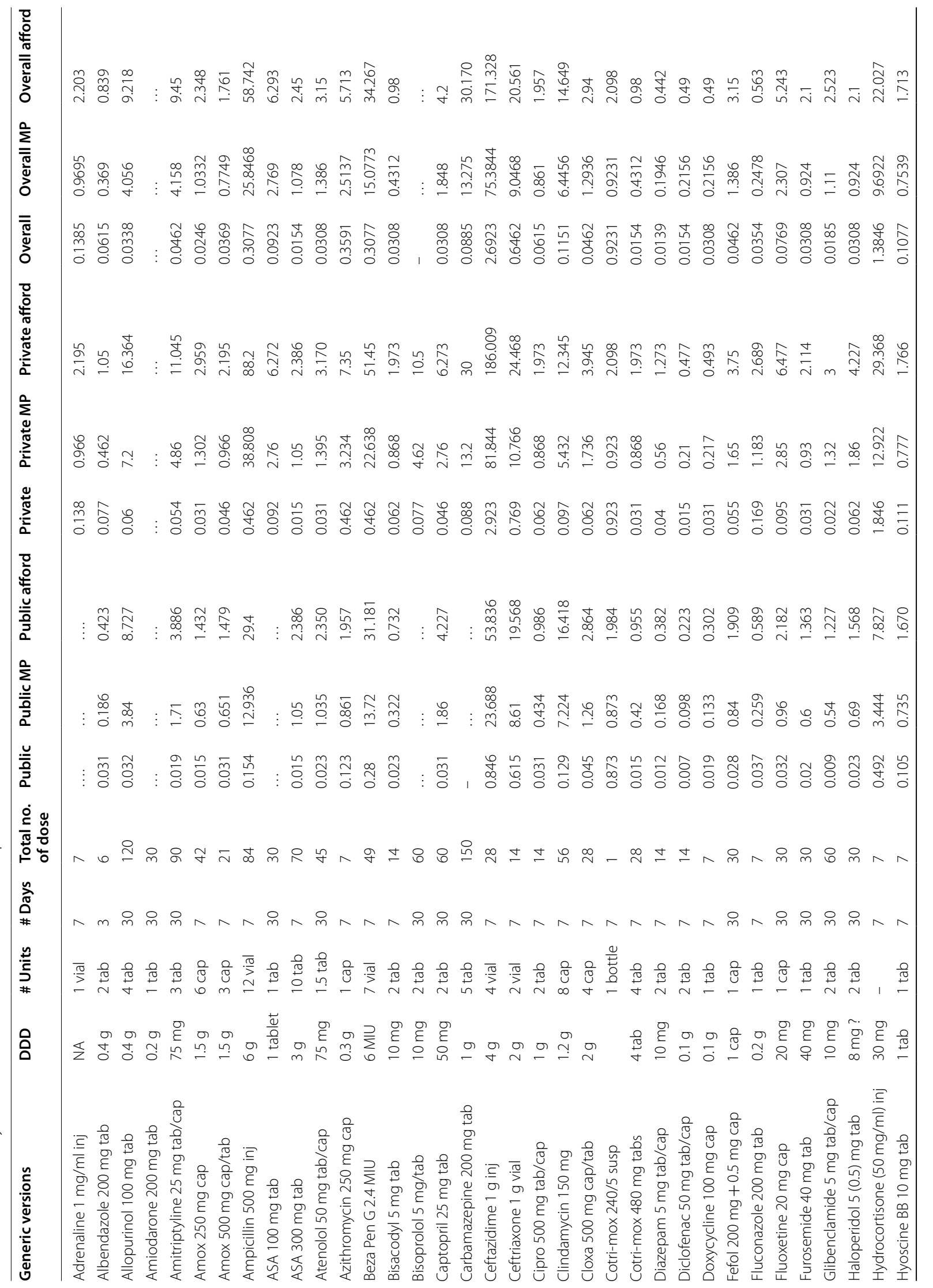




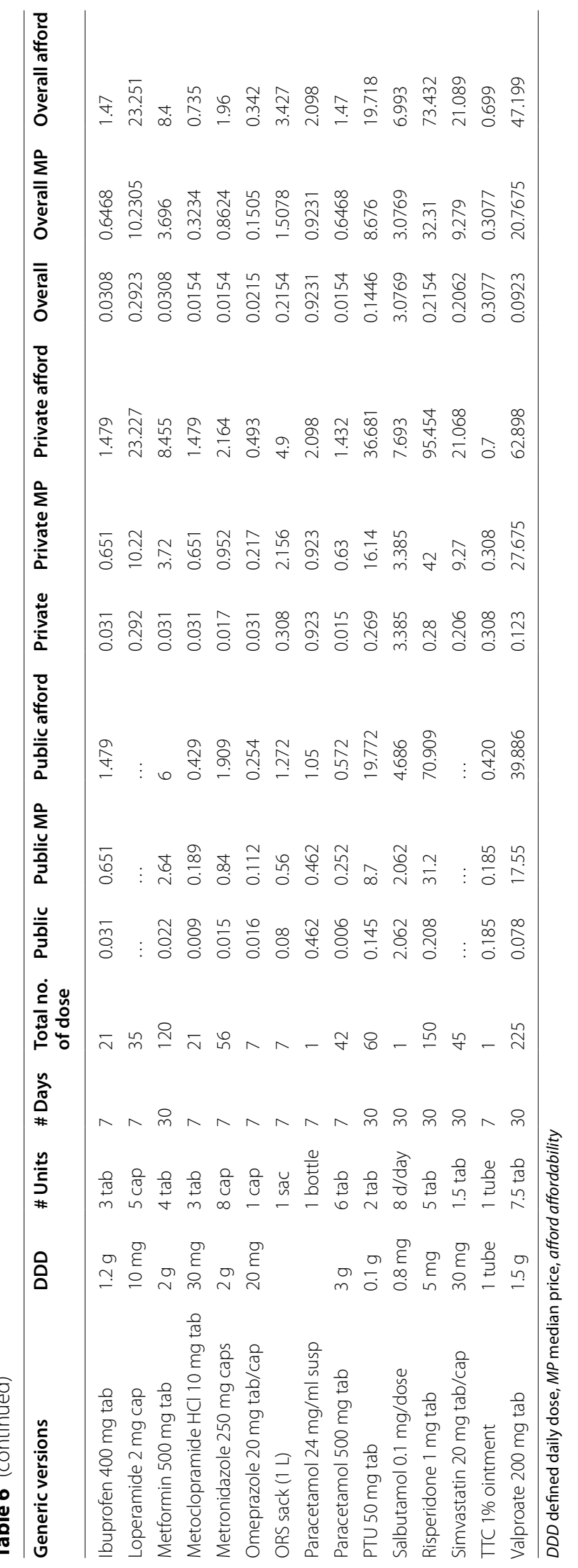


reliable and standardized way. Utilization of international reference prices can also allow for valid international comparisons between Ethiopia and other countries. Besides, we considered global core, regional and national essential medicines for international comparison. However, being a single point cross-sectional study, it is unable to reflect the average monthly or annually availability of medicines at individual outlets. The affordability section is also heavily dependent on the economic status, public salary scale, and exchange power of Ethiopian birr and subject to change over time.

\section{Conclusion}

The overall availability of generic versions of essential medicines was by far lower than the WHO target of $80 \%$ with $16 \%$ of the surveyed medicines surpassing the cutoff point. The overall availability of OBs was also less than $5 \%$. About $30 \%$ of drugs in the private sector had a price of more than four times (MPR threshold) than that of the international references. Moreover, four out of five drugs were found unaffordable when both settings were combined. Looking at the private sector, about nine from ten drugs demanded several days of wages of lowest paid government employees. There is a higher tendency of prescribing generics than the $\mathrm{OB}$ versions of essential medicines as the $\mathrm{OB}$ versions are much more expensive in such resource limited settings. However, much is yet to be invested in controlling the price of drugs. Ensuring access of essential medicines is one of the general objectives of Ethiopian National Drug Policy. In this regard, the current regional study indicates the availability and affordability is suboptimal which calls the responsible stakeholders to devise a strategy that help increase the access of essential medicines and rescue the struggling healthcare system.

\section{Acknowledgements}

The authors thank data collectors and staff of all healthcare settings for their substantial help to realize this research work. The authors also extend their thank to Haramaya University for granting this research work.

\section{Authors' contributions}

All authors have contributed to the conception of the original idea, study design and data collection. MS analyzed the data; MS and FA drafted the manuscript. BH and DE critically revised it. All authors have read and approved the final manuscript.

\section{Funding}

The authors disclosed reception of financial support from Haramaya University for conducting this research work.

\section{Availability of data and materials}

All the data used for the study are contained within the manuscript.

\section{Declarations}

\section{Competing interests}

The authors have declared that there is no competing interests exist.

\section{Author details}

${ }^{1}$ Department of Pharmacology and Toxicology, School of Pharmacy, College of Health and Medical Sciences, Haramaya University, P.O. Box 235, Harar, Ethiopia. ${ }^{2}$ Department of Clinical Pharmacy, School of Pharmacy, College of Health and Medical Sciences, Haramaya University, P.O. Box 235, Harar, Ethiopia. ${ }^{3}$ Department of Social Pharmacy, School of Pharmacy, College of Health and Medical Sciences, Haramaya University, P.O. Box 235, Harar, Ethiopia.

Received: 13 April 2021 Accepted: 24 June 2021

Published online: 05 July 2021

\section{References}

1. Castillo CHM, Garrafa V, Cunha T, Hellmann F. El acceso a la salud como derecho humano en políticas internacionales: reflexiones críticas y desafíos contemporáneos. Cien Saude Colet. 2017;22:2151-60.

2. WHO. Health in 2015: from MDGs to SDGs. 2015.

3. Bigdeli M, Laing R, Tomson G, Babar Z-U-D. Medicines and universal health coverage: challenges and opportunities. J Pharm Policy Pract. 2015;8(1):8.

4. Wirtz VJ, Hogerzeil HV, Gray AL, Bigdeli M, de Joncheere CP, Ewen MA, et al. Essential medicines for universal health coverage. Lancet (London, England). 2017;389(10067):403-76.

5. Ozawa S, Shankar R, Leopold C, Orubu S. Access to medicines through health systems in low- and middle-income countries. Health Policy Plan. 2019;34(Supplement_3):iii1-3.

6. WHO. Access to medicines: making market forces serve the poor 2017.

7. Ahmadiani S, Nikfar S. Challenges of access to medicine and the responsibility of pharmaceutical companies: a legal perspective. DARU J Faculty Pharm Sci. 2016;24(1):13.

8. Perehudoff SK, Alexandrov NV, Hogerzeil HV. Legislating for universal access to medicines: a rights-based cross-national comparison of UHC laws in 16 countries. Health Policy Plan. 2019;34(Supplement_3):iii48-57.

9. WHO. Essential medicines. 2015

10. Kar SS, Pradhan HS, Mohanta GP. Concept of essential medicines and rational use in public health. Indian J Commun Med. 2010;35(1):10-3.

11. Peters DH, Garg A, Bloom G, Walker DG, Brieger WR, Rahman MH. Poverty and access to health care in developing countries. Ann NY Acad Sci. 2008;1136:161-71.

12. Alsairi R. Access to medicine in developing countries. Am J Med Sci. 2017;7(6):271-6.

13. Gronde TV, Uyl-de Groot CA, Pieters T. Addressing the challenge of highpriced prescription drugs in the era of precision medicine: a systematic review of drug life cycles, therapeutic drug markets and regulatory frameworks. PLoS ONE. 2017;12(8): e0182613.

14. Cameron AHS, Whyte P, Ramsey S, Hedman L. WHO guideline on country pharmaceutical pricing policies. WHO. 2015.

15. Zarif-Yeganeh M, Kargar M, Rashidian A, JafarzadehKohneloo A, Gholami $\mathrm{K}$. Out of pocket payment and affordability of medication for geriatric patients in Tehran, Iran. Iran J Public Health. 2019;48(6):1124-32.

16. WHO/HAl. Measuring medicine prices, availability, affordability and price components. 2nd ed. Geneva, Switzerland 2008.

17. WHO/HAI. Measuring medicine prices, availability, affordability and price components World Health Organization \& Health Action International. 2nd edn. 2016. 123-289.

18. Raju PKS. Chapter 6.2-WHO/HAl methodology for measuring medicine prices, availability and affordability, and price components. In: Vogler $\mathrm{S}$, editor. Medicine price surveys, analyses and comparisons. Academic Press: Cambridge; 2019. p. 209-28.

19. Carasso BS, Lagarde M, Tesfaye A, Palmer N. Availability of essential medicines in Ethiopia: an efficiency-equity trade-off? Trop Med Int Health. 2009;14(11):1394-400.

20. FMHACA. List of essential medicines for Ethiopia. Food, medicine and healthcare administration and control authority of Ethiopia. 4th edn. Addis Ababa. 2010.

21. Wirtz VJ, Hogerzeil HV, Gray AL, Bigdeli M, de Joncheere CP, Ewen $M A$, et al. Essential medicines for universal health coverage. Lancet. 2017;389(10067):403-76. 
22. WHO. World Health Organization model list of essential medicines: $21 \mathrm{st}$ list 2019. World Health Organization, 2019.

23. Atif M, Malik I, Dawoud D, Gilani A, Ahmed N, Babar Z-U-D. Essential medicine list, policies, and the world health organization. In: Babar ZUD, editor. Encyclopedia of pharmacy practice and clinical pharmacy. Elsevier: Oxford; 2019. p. 239-49.

24. WHO. The selection and use of essential medicines: report of the WHO Expert Committee, 2017 (including the 20th WHO model list of essential medicines and the 6th model list of essential medicines for children): World Health Organization; 2017.

25. MoH/EFDA. Ethiopian Essential Medicines List. 2020.

26. Mahmić-Kaknjo M, Jeličić-Kadić A, Utrobičić A, Chan K, Bero L, Marušić A. Essential medicines availability is still suboptimal in many countries: a scoping review. J Clin Epidemiol. 2018;98:41-52.

27. Bissell K, Perrin C, Beran D. Access to essential medicines to treat chronic respiratory disease in low-income countries. Int J Tuberc Lung Dis. 2016;20(6):717-28.

28. Khatib R, McKee M, Shannon H, Chow C, Rangarajan S, Teo K, et al. Availability and affordability of cardiovascular disease medicines and their effect on use in high-income, middle-income, and low-income countries: an analysis of the PURE study data. Lancet. 2016;387(10013):61-9.

29. Rida NA, Ibrahim MM, Babar Z. Relationship between pharmaceutical pricing strategies with price, availability, and affordability of cardiovascular disease medicines: surveys in Qatar and Lebanon. BMC Health Serv Res. 2019;19(1):1-14.

30. Abrha S, Tadesse E, Atey TM, Molla F, Melkam W, Masresha B, et al. Availability and affordability of priority life-saving medicines for under-five children in health facilities of Tigray region, northern Ethiopia. BMC Pregnancy Childbirth. 2018;18(1):1-9.

31. Alefan Q, Amairi R, Tawalbeh S. Availability, prices and affordability of selected essential medicines in Jordan: a national survey. BMC Health Serv Res. 2018;18(1):1-12.

32. Ahmad NS, Islahudin F. Affordability of essential medicine prices in Malaysia's private health sector. Patient Prefer Adher. 2018;12:1231.

33. Ewen M, Zweekhorst M, Regeer B, Laing R. Baseline assessment of WHO's target for both availability and affordability of essential medicines to treat non-communicable diseases. PLoS ONE. 2017;12(2): e0171284.

34. Ewen M, Kaplan W, GedifT, Justin-Temu M, Vialle-Valentin C, Mirza Z, et al. Prices and availability of locally produced and imported medicines in Ethiopia and Tanzania. J Pharm Policy Pract. 2017:10(1):1-9.

35. Mendis S, Fukino K, Cameron A, Laing R, Filipe A Jr, Khatib O, et al. The availability and affordability of selected essential medicines for chronic diseases in six low-and middle-income countries. Bull World Health Organ. 2007:85:279-88.

36. Nguyen TA, Knight R, Roughead EE, Brooks G, Mant A. Policy options for pharmaceutical pricing and purchasing: issues for low-and middleincome countries. Health Policy Plan. 2015;30(2):267-80.

37. Bizimana T, Kayumba PC, Heide L. Prices, availability and affordability of medicines in Rwanda. PLoS ONE. 2020;15(8): e0236411.

38. Khanal S, Veerman L, Ewen M, Nissen L, Hollingworth S. Availability, price, and affordability of essential medicines to manage noncommunicable diseases: a national survey from Nepal. INQUIRY J Health Care Organ Provis Financ. 2019;56: 0046958019887572

39 Saeed A, Saeed H, Saleem Z, Fang Y, Babar Z-U-D. Evaluation of prices, availability and affordability of essential medicines in Lahore Division, Pakistan: a cross-sectional survey using WHO/HAl methodology. PLoS ONE. 2019;14(4): e0216122.

40. Sun X, Wei J, Yao Y, Chen Q, You D, Xu X, et al. Availability, prices and affordability of essential medicines for children: a cross-sectional survey in Jiangsu Province, China. BMJ Open. 2018;8(10): e023646.

41. Wang H, Sun Q, Vitry A, Nguyen TA. Availability, price, and affordability of selected essential medicines for chronic diseases in 11 countries of the Asia Pacific region: a secondary analysis. Asia Pac J Public Health. 2017:29(4):268-77.
42. Wong SL, Ibrahim S, Kadir NA, Salleh SM. Access and affordability of medicines in Malaysia: need for a national pricing policy. Appl Health Econ Health Policy. 2019;17(5):641-54.

43. Wu G, Gong S, Cai H, Ding Y. The availability, price and affordability of essential antibacterials in Hubei province, China. BMC Health Serv Res. 2018;18(1):1-8.

44. Xi X, Li W, Li J, Zhu X, Fu C, Wei X, et al. A survey of the availability, prices and affordability of essential medicines in Jiangsu Province China. BMC Health Serv Res. 2015;15(1):1-7.

45. Xu R, Li S, LvX, Xie X. Prices, availability, and affordability of national essential medicines in public primary hospitals: a cross-sectional survey in poverty-stricken rural areas in China. Int J Health Plan Manag. 2020;35(2):545-57.

46. Attaei MW, Khatib R, McKee M, Lear S, Dagenais G, Igumbor EU, et al. Availability and affordability of blood pressure-lowering medicines and the effect on blood pressure control in high-income, middle-income, and low-income countries: an analysis of the PURE study data. Lancet Public Health. 2017;2(9):e411-9.

47. Chow CK, Ramasundarahettige C, Hu W, AlHabib KF, Avezum A Jr, Cheng $X$, et al. Availability and affordability of essential medicines for diabetes across high-income, middle-income, and low-income countries: a prospective epidemiological study. Lancet Diabetes Endocrinol. 2018;6(10):798-808

48 Babar Z-U-D, Ramzan S, El-Dahiyat F, Tachmazidis I, Adebisi A, Hasan SS. The availability, pricing, and affordability of essential diabetes medicines in 17 low-, middle-, and high-income countries. Front Pharmacol. 2019;10:1375.

49. Shrestha R, Ghale A, Chapagain BR, Gyawali M, Acharya T. Survey on the availability, price and affordability of selected essential medicines for non-communicable diseases in community pharmacies of Kathmandu valley. SAGE Open Med. 2017;5:2050312117738691.

50. Kaiser AH, Hehman L, Forsberg BC, Simangolwa WM, Sundewall J. Availability, prices and affordability of essential medicines for treatment of diabetes and hypertension in private pharmacies in Zambia. PLoS ONE. 2019;14(12): e0226169.

51. Kasonde L, Tordrup D, Naheed A, Zeng W, Ahmed S. Evaluating medicine prices, availability and affordability in Bangladesh using World Health Organisation and Health Action International methodology. BMC Health Serv Res. 2019;19(1):1-12.

52. Khuluza F, Haefele-Abah C. The availability, prices and affordability of essential medicines in Malawi: a cross-sectional study. PLoS ONE. 2019:14(2): e0212125.

53. Gelders S, Ewen M, Noguchi N, Laing R. Price, availability and affordability. An international comparison of chronic disease medicines Cairo: World Health Organization Regional Office for the Eastern Mediterranean 2006.

54. Su M, Zhang Q, Bai X, Wu C, Li Y, Mossialos E, et al. Availability, cost, and prescription patterns of antihypertensive medications in primary health care in China: a nationwide cross-sectional survey. Lancet. 2017;390(10112):2559-68.

55. Perehudoff SK, Alexandrov NV, Hogerzeil HV. Access to essential medicines in 195 countries: a human rights approach to sustainable development. Glob Public Health. 2019;14(3):431-44.

56. Klein EY, Milkowska-Shibata M, Tseng KK, Sharland M, Gandra S, Pulcini C, et al. Assessment of WHO antibiotic consumption and access targets in 76 countries, 2000-15: an analysis of pharmaceutical sales data. Lancet Infect Dis. 2021;21(1):107-15.

57. Moye-Holz D, van Dijk JP, Reijneveld SA, Hogerzeil HV. Policy approaches to improve availability and affordability of medicines in Mexico —an example of a middle income country. Glob Health. 2017;13(1):1-10.

\section{Publisher's Note}

Springer Nature remains neutral with regard to jurisdictional claims in published maps and institutional affiliations. 